\title{
Eficácia direta e imediata do princípio constitucional da sustentabilidade
}

\section{Direct and immediate implementation of the constitutional principle of sustainability}

\author{
Juarez Freitas \\ Pontifícia Universidade Católica - PUC/RS - Porto Alegre - Rio Grande do Sul - Brasil \\ Universidade Federal do Rio Grande do Sul - UFRGS - - Porto Alegre - Rio Grande do Sul - \\ Brasil
}

Resumo: O princípio constitucional da sustentabilidade, reconhecido em sua eficácia direta e imediata, acarreta profundas alterações no processo das escolhas públicas, porque o Estado resulta obrigado a orientar, induzir, adequar e regular as condutas, no rumo daquele desenvolvimento propício à proteção dos direitos fundamentais das gerações presentes e futuras. Em todas as etapas da tomada da decisão pública (da fase interna até a implementação), cumpre realizaro escrutínio, baseado em evidências, do acatamento da sustentabilidade como dever fundamental, não mera faculdade (exposta a juízos de conveniência ou oportunidade). Impõe-se, em outras palavras, cobrar as políticas públicas que transformem os modos de produção e consumo, de maneira a instaurar o ambiente ecologicamente equilibrado, mediante ponderação justificada de custos e benefícios, diretos e indiretos.

Palavras-chave: Direitos fundamentais; Sustentabilidade; Eficácia.

Abstract: The constitutional principle of sustainability, recognized in its direct and immediate effect, produces deep changes in the process of public choices, because the State results obliged to guide, to lead, to adjust and to regulate the conducts in the direction of that development compatible with the protection fundamental of rights for present and future generations. At all stages of making public decisions (since the internal phase to the implementation phase), it should make the ballot, based on evidence of sustainability as a fundamental duty, not a mere option (exposed to the convenience of subjective judgments or opportunity). In other words, there must be public policies able to transform the modes of production and consumption, in order to establish the ecologically balanced environment, upon a justified weighting of costs and benefits, direct and indirect.

Keywords: Fundamental Rights; Sustainability; Effectiveness.

Revista do Direitoda UNISC, Santa Cruz do Sul, v.1, n. 45, p. 89-103, jan. - abri. 2015. 


\section{INTRODUÇÃO}

No sistema brasileiro, a incidência do princípio constitucional da sustentabilidade implica profundo redesenho de todo o sistema jurídico e do modo de concebê-lo. Afortunadamente, começa a ser reconhecida a eficácia direta e imediata do desenvolvimento sustentável em todas as províncias do ordenamento. Bem observado, esse dever ubíquo de incorporar os critérios de sustentabilidade ao processo de escolhas públicas - na linha do que assimilaram, em boa hora, o Conselho Nacional de Justiça e o Tribunal de Contas da União ${ }^{1}$ - decorre, antes de mais nada, do sistema constitucional (CF, arts. 3o, 170, VI e 225), que determina ao Estado orientar, induzir, adequar e regular as condutas, públicas e privadas ${ }^{2}$, para que se mostrem produtivamente conducentes àquele desenvolvimento propício à proteção dos direitos fundamentais das gerações presentes e futuras.

Trata-se de mandamento constitucional intergeracional que exige clarificar os objetivos ${ }^{3}$ do desenvolvimento sustentável, no rol das diretrizes que condicionam os procedimentos públicos. ${ }^{4}$ De tais objetivos emerge, por assim dizer, inovadora filosofia de governança, sob a influência da qual passam a ser inseridas métricas que permitem uma ponderação acurada de custos e benefícios, diretos e indiretos.

Em todas as etapas da tomada de decisão pública (da crucial fase interna até a implementação), cumpre respeitar e fazer respeitar a sustentabilidade como princípio cogente, não mera faculdade (exposta aos juízos voláteis de conveniência ou oportunidade). Impõe-se, em outras

\footnotetext{
${ }^{1}$ Ver Resolução 201, de março de 2015, do CNJ. Em boa hora, o TCU aprovou resolução que criou a Política Institucional de Sustentabilidade do Tribunal. Vide Acórdão 329/2015. Vide, ainda, Acórdão 4529/2012. Na esfera dos Estados, ver, para ilustrar, a Resolução 976/2013, do TCERS.

2 Ver a Resolução 4.327, de 2014, do Banco Central, que trata da responsabilidade socioambiental das instituições financeiras, públicas e privadas.

${ }^{3}$ Em 2015, a ONU definirá, em setembro, em Nova York, os Objetivos do Desenvolvimento Sustentável.

${ }^{4} \mathrm{~A}$ essa altura, não cabe dúvida séria sobre o fato de que a Constituição consagra o princípio da sustentabilidade, em suas entrelaçadas dimensões, quais sejam, a social, a ambiental, a econômica e a ética. O conceito de sustentabilidade, aqui defendido, é o de princípio constitucional que determina, com eficácia direta e imediata, a responsabilidade do Estado e da sociedade pela concretização solidária do desenvolvimento material e imaterial, socialmente inclusivo, durável e equânime, ambientalmente limpo, inovador, ético e eficiente, no intuito de assegurar, no presente e no futuro, o direito ao bem-estar. Sobre o conceito e reflexos no Direito Administrativo, ver FREITAS (2012), especialmente Caps. 1 e 9.
}

Revista do Direitoda UNISC, Santa Cruz do Sul, v.1, n. 45, p. 89-103, jan. - abri. 2015. 
palavras, reforjar juridicamente os modos de produção ${ }^{5}$ e consumo, de maneira a instaurar um ambiente ecologicamente equilibrado, colorido com as tonalidades vibrantes da equidade intergeracional.

Consoante essa perspectiva, eis as premissas medulares do presente estudo:

(a) a sustentabilidade, no sistema brasileiro, é princípio de estatura constitucional (CF, arts. 3ำ $\left.225^{6}, 170, \mathrm{VI}\right)$, aplicável no âmbito dos procedimentos públicos e privados, tendo como escopo a tutela peculiar de direitos fundamentais da terceira dimensão; ${ }^{7}$

(b) os procedimentos públicos, administrativos e tributários ${ }^{8}$, devem contribuir, de modo sincronizado, para internalizar as externalidades, com a priorização fática e jurídica das escolhas ligadas ao bem-estar duradouro (núcleo deontológico do princípio em apreço);

(c) mediante adoção de mais completa matriz de riscos, o controle dos procedimentos públicos deve operar com modelos paramétricos de evidências, pois a melhor solução tem de estar associada a menores impactos negativos e, concomitantemente, a maiores vantagens globais.

Com base nessas premissas de fundo, postula-se, assim, um aperfeiçoamento sem precedentes das políticas públicas, no sentido deliberado e consistente de harmonizá-las com o desenvolvimento sustentável.

\footnotetext{
${ }^{5}$ Ver, no Direito Comparado, o plano norte-americano de 2014 da Agência de Proteção Ambiental (EPA), segundo o qual, até 2030, as operadoras de usinas de geração de energia elétrica terão que reduzir em $30 \%$ as emissões de dióxido de carbono.

${ }^{6}$ Vide decisão do STF: "Princípios constitucionais (art. 225) do desenvolvimento sustentável e da equidade e responsabilidade intergeracional. Meio ambiente ecologicamente equilibrado: preservação para a geração atual e para as gerações futuras. Desenvolvimento sustentável: crescimento econômico com garantia paralela e superiormente respeitada da saúde da população, cujos direitos devem ser observados em face das necessidades atuais e daquelas previsíveis e a serem prevenidas para garantia e respeito às gerações futuras. (...)(ADPF 101, Rel. Min. Cármen Lúcia Rocha)

${ }^{7}$ Ver decisão do STF: "Enquanto os direitos de primeira geração (direitos civis e políticos) - que compreendem as liberdades clássicas, negativas ou formais - realçam o princípio da liberdade e os direitos de segunda geração (direitos econômicos, sociais e culturais) - que se identificam com as liberdades positivas, reais ou concretas - acentuam o princípio da igualdade, os direitos de terceira geração, que materializam poderes de titularidade coletiva atribuídos genericamente a todas as formações sociais, consagram o princípio da solidariedade e constituem um momento importante no processo de desenvolvimento, expansão e reconhecimento dos direitos humanos, caracterizados, enquanto valores fundamentais indisponíveis, pela nota de uma essencial inexauribilidade." (MS 22.164, Rel. Min. Celso de Mello)

${ }^{88}$ Ver, no Direito Comparado, FERNÁNDEZ (2011).
}

Revista do Direitoda UNISC, Santa Cruz do Sul, v.1, n. 45, p. 89-103, jan. - abri. 2015. 


\section{POLÍTICAS PÚBLICAS E O PRINCÍPIO DA SUSTENTABILIDADE}

Políticas públicas sustentáveis são aqui conceituadas como programas de Estado Constitucional (mais do que governativos) que conferem primazia ao desenvolvimento duradouro, material e imaterial. Supõem, nessa medida, o qualificado induzimento ao consumo e à produção inteligentes, com o propósito de preparar, em larga escala, uma sociedade inclusiva e saudável. Para viabilizar tais políticas, a tomada da decisão estatal terá de ser precedida de inédita avaliação de impactos sociais, econômicos e ambientais, por ações e omissões, em lugar de estimativas ingênuas, toscas e inconsequentes.

Nesse prisma, qualquer ação pública (administrativa, legislativa e jurisdicional) precisa contemplar os riscos e os ganhos não apenas econômicos, mas ambientais e sociais. Para ilustrar, o sistema administrativo e tributário tem de reorientar a matriz energética para a eficiência, a reciclagem e a prioridade das energias renováveis, em vez de se imantar pelo fascínio imediatista dos fósseis.

Tudo isso pressupõe a troca do decisionismo patrocinado por interesses subalternos para uma decisão equitativa, consistentemente motivada e proba. Apenas desse modo, o pensamento de longo prazo terá chance de "descarbonizar" a economia, a esfera jurídica e a política, limpando-as e destronando a retórica do engano e do autoengano.

A partir daí, as políticas públicas sustentáveis (cientificamente informadas) terão vez e voto. Quando isso ocorrer, emergirá o desenvolvimento justo, voltado para aquilo que realmente importa: a qualidade de vida, assegurada a todos como direito irrenunciável ao futuro. ${ }^{9}$

Em outras palavras, as políticas públicas sustentáveis são programas que o Poder Público deve enunciar e implementar de acordo com as prioridades vinculantes da Carta, de ordem a assegurar a efetividade do plexo de direitos fundamentais das gerações presentes e futuras (FREITAS, 2014, p. 32). Indefensável, por exemplo, efetuar uma licitação pública sem considerar os custos de manutenção e os impactos sistêmicos sobre a saúde da

\footnotetext{
${ }^{9}$ Ver BAUMAN (2008, p. 105), quando afirma que: "A qualidade humana da sociedade deveria ser medida pela qualidade de vida dos seus membros mais fracos."
}

Revista do Direitoda UNISC, Santa Cruz do Sul, v.1, n. 45, p. 89-103, jan. - abri. 2015. 
população. ${ }^{10}$ Afigura-se, de outra parte, manifesta a insustentabilidade de empréstimos públicos desacompanhados de cautelas sociais e ambientais, além das econômicas. ${ }^{11}$

Dito de modo direto, importa assimilar que as politicas públicas, sem exceção, têm de estar preordenadas para promover, de modo diligente e em tempo útil, a harmonização efetiva dos vetores ambientais, sociais e econômicos, contribuindo, assim, à superação da chamada tragédia dos comuns. ${ }^{12}$

Quer dizer, não apenas se impõem práticas eficientes de racionalização dos meios, mas a gestão sustentável de processos, com o monitoramento finalístico de qualidade, a par da imprescindível capacitação para conceber e fiscalizar procedimentos com semelhante desiderato.

Com efeito, o procedimento licitatório é emblemático para evidenciar como a decisão pública pode ser prestimosa para "controlar a produção, a comercialização e o emprego de técnicas, métodos e substâncias que comportem risco para a vida, a qualidade de vida e o meio ambiente." ${ }^{13}$

Ao licitar, o Estado-Administração é chamado a densificar o princípio da sustentabilidade, em consórcio indissolúvel com os demais princípios, ${ }^{14}$ eis que, no limite, a obra ineficiente, o serviço nefasto, o financiamento temerário e o produto nocivo compõem o quadro de violações frontais ao princípio em tela. Nessa medida, a solução pública mais vantajosa será somente aquela que se apresentar apta a produzir, direta ou indiretamente, o menor impacto negativo e, simultaneamente, os maiores benefícios econômicos, sociais e ambientais.

É que, ao tomar decisões públicas, não se podem ignorar, candidamente, os efeitos futuros, por maior que seja a incerteza. Um dos erros crônicos tem sido o de não (querer) enxergar, por exemplo, que a manutenção precisa ser contratada segundo a lógica do longo prazo, escolhido o material mais duradouro e resiliente. Na lógica dominante, o contratado tende, não raro,

\footnotetext{
${ }^{10}$ Estudo da Agência Internacional para a Pesquisa do Câncer, ligada à Organização Mundial da Saúde, evidencia a poluição atmosférica como uma das principais causas de mortes por câncer.

${ }^{11}$ Ver a mencionada Resolução 4.327, de 2014, do Banco Central do Brasil, que define o risco socioambiental.

${ }^{12}$ Ver, sobretragédia dos comuns, SALZMAN e THOMPSON JR (2010, p. 19): "individual rational behavior is collectively deficient. Individual's personal incentives work against the best long-term solution."

${ }^{13}$ Ver CF, art. 225, par. $1^{\circ}, \mathrm{V}$.

${ }^{14}$ Trata-se - convém reiterar - de diretriz vinculante. Vide, a propósito, Lei 6.938/81, art. $4^{\circ}$, VII.
}

Revista do Direitoda UNISC, Santa Cruz do Sul, v.1, n. 45, p. 89-103, jan. - abri. 2015. 
a fazer simples remendos, de maneira que logo surgem onerosas recontratações de curta duração. Evidencia-se, nesse caso, o erro crasso e corriqueiro de arquitetura intertemporal dos procedimentos públicos.

Em contraste, o procedimento sustentável é capaz de contemplar, ao mesmo tempo, a manutenção e a ampliação gradativa de capacidade, eficiência e produtividade, sempre em horizonte que transcende os calendários eleitorais. Cabe, pois, ao Estado-Administração encorajar e cobrar que os atores sociais passem a concretizar o princípio da sustentabilidade ${ }^{15}$ - desde a obtenção de matérias-primas e dos insumos, passando pelo processo produtivo e consumo até a disposição final ou pós-consumo. Não se trata de simples predileção de agente idealista e engajado, mas de incontornável obrigação jurídica.

Note-se, de passagem, que a Lei de Resíduos Sólidos ${ }^{16}$ consagra, de modo categórico, o princípio do desenvolvimento sustentável (art.6ํㅡ, IV) e estabelece a prioridade ( $\operatorname{art}^{7} 7^{\circ}, \mathrm{XI}$ ), nas aquisições e contratações públicas, para os produtos reciclados ou recicláveis e para os bens, serviços e obras que correspondam a padrões da economia de baixo carbono. Prioridade, no enunciado normativo, não pode ser interpretada como mera faculdade, menos ainda como singela preferência. ${ }^{17}$

Em paralelo, quadra reconhecer, vez por todas, que o custo de investir no monitoramento do uso de recursos naturais requer investimento de " $x$ ", contudo tende a proporcionar, ao longo do tempo, economia da ordem de várias vezes "x." Outra vez: a adoção, em larga escala, de procedimentos públicos direcionados à ecoeficiência (obtendo mais com menos recursos naturais ${ }^{18}$ ) não é simples escolha, escrava dos enviesados juízos de conveniência e de oportunidade, porém mandamento jurídicoa ser observado à risca.

Pois bem. Arrolem-se, a título ilustrativo, adicionais aplicações do princípio da sustentabilidade, no âmbito da tomada de decisão pública:

\footnotetext{
${ }^{15}$ Ver Lei 12.305 , de 2010 , art. $3^{\circ}$, IV, sobre o ciclo de vida do produto.

${ }^{16}$ Ver Lei 12.305, de 2010.

${ }^{17}$ Ver o Código Florestal (Lei 12.651, de 2012), que, a despeito de retrocessos pontuais, explicita regras de controle de origem dos produtos florestais (arts. 35, 36 e 37).

${ }^{18}$ No ranking do American Councilfor na Energy-EfficienteEconomy, o Brasil está em 15임 lugar em termos de eficiência energética, nos termos do relatório "The 2014 International Energy Efficiency Scorecard." Daí a relevância estratégica de considerar a eficiência energética uma prioridade-chave.
}

Revista do Direitoda UNISC, Santa Cruz do Sul, v.1, n. 45, p. 89-103, jan. - abri. 2015. 
(a) Os edifícios públicos podem-devem ser construídos com tecnologias "verdes," ${ }^{19}$ de modo a distribuir energia excedente. ${ }^{20}$

(b) Os programas de moradias destinadas às famílias de baixa renda precisam, desde já, incluir a energia solar térmica. ${ }^{21}$

(c) As merendas escolares não apenas têm que ser oferecidas, compreferência, por fornecedores locais, senão que devem ser compostas de alimentos isentos de venenos cancerígenos. ${ }^{22}$

(d) A construção em área contaminada simplesmente não pode ser tolerada até que se proceda a completa descontaminação.

(e) Os projetos básicos e executivos, para a contratação pública de obras e serviços de engenharia, estão, desde já, obrigados a contemplar opções redutoras dos custos de manutenção e de operacionalização, não apenas os de construção.

(f) Os veículos adquiridos pelo Poder Público têm de ser os menos poluentes, isto é, dotados de rigorosos controles de emissão, no intuito de enfrentar a poluição que, nos grandes centros, assume proporções alarmantes e, não raro, fatais.

(g) As políticas de transporte devem levar em conta o caráter prioritário do transporte público de qualidade, ${ }^{23}$ assim como o incremento de alternativos modais de transportes (ferrovias e hidrovias) para o escoamento de pessoas e produção, haja vista a saturação crítica do modal rodoviário. ${ }^{24}$ (O trânsito,

\footnotetext{
${ }^{19}$ Ver, a propósito, iniciativa da ONU, intitulada "Década da Energia Sustentável para Todos" (2014-2024), lançada na Conferência Bloomberg de Finanças para as Novas Energias, em New York.

${ }^{20}$ Vide a Resolução Normativa 482, de 2012, da Aneel, sobre condições gerais para o acesso de microgeração e minigeração distribuída aossistemas de distribuição de energia elétrica.

${ }^{21} \mathrm{O}$ fornecimento suficiente de energia, com tarifas módicas, é uma das principais demandas brasileiras. Justifica-se, pois, defender a obrigatoriedade de instalar aquecedores solares em todas as moradias do programa "Minha Casa, Minha Vida."

${ }^{22}$ Ver a experiência de Itaipu, no Programa Cultivando Água Boa, em parceria com municípios lindeiros ao lago, com avanços significativos em projetos de educação ambiental e agricultura orgânica.

${ }^{23}$ Vide o Comunicado do IPEA 113, Poluição Veicular Atmosférica, setembro de 2011, p. 24 , que aposta em alternativas tecnológicas limpas e, em lugar de políticas contraditórias que favorecem o transporte individual, postula a prioridade do transporte coletivo. Ora, a partir do advento da Lei de Mobilidade Urbana, em 2012, o mundo jurídico consagra tal perspectiva. Vide a propósito, Relatório do TCE/SC, RLA-1300759493, escrutinando o cumprimento da Política Nacional de Mobilidade Urbana.

${ }^{24}$ Ver, sobre o sistema intermodal, GIAMBIAGI e BARROS (2009, p. 320).
}

Revista do Direitoda UNISC, Santa Cruz do Sul, v.1, n. 45, p. 89-103, jan. - abri. 2015. 
especialmente nas metrópoles, ${ }^{25}$ é estressante testemunho da falta de planejamento sistêmico e do enviesamento do "status quo.") ${ }^{26}$

(h) No atinente aos procedimentos relativos a compras sustentáveis, a Administração Pública pode-deve servir de modelo inspirador do consumo racional, ${ }^{27}$ no exercício do seu poder indutor, passível de aferição em auditorias operacionais. ${ }^{28}$ Ou seja, a partir do criterioso levantamento de opções, ${ }^{29}$ impõese conferir atenção ao ciclo de vida dos bens, adquirindo somente o necessário e zelando pela qualidade de origem e destinação. (A gestão sustentável de suprimentos ${ }^{30}$ opera com uma equação de custo-benefício que inclui variáveis não somente econômicas. Reitere-se que não se trata de simples faculdade. Trata-se de poder-dever).

Assentado o ponto relativo à obrigatoriedade da tomada de decisões públicas sustentáveis, infere-se que o controle necessário tem de ser remodelado para cobrar a eficácia intertemporal das políticas adotadas, em vez do formalismo vazio e da eficiência de fachada. É que o formalismo e a eficiência, em situações paradoxais, produzem mais velozmente 0 insustentável, como atesta o famoso "paradoxo de Jenvons." (1866)Daí se preconizar a ecoficiência (em vez da eficiência utilitária) como poderosa aliada do princípio da eficácia intertemporal.

Regras para isso, no sistema brasileiro, não faltam. Podem ser catalogadas em três grandes grupos: (i) regras legais; (ii) regras administrativas, decorrentes do poder regulamentar e (iii) regras extraíveis do sistema, as quais servem para colmatar lacunas e suprir pontual carência de disposição expressa.

\footnotetext{
${ }^{25}$ Cidades fazem esforço meritório para vencer gargalos, como Copenhague e Oslo. Em toda parte, porém, requer-se acentuada mudança de concepção e de planejamento dos centros urbanos, muitos dos quais verdadeiramente impróprios para a vida saudável.

${ }^{26}$ VerSAMUELSON e ZECKHAUSER (1988, p. 8): "The main finding is that decision makers exhibit a significant status quo bias. Subjects in our experiments adhered to status quo choices more frequently than would be predicted by the canonical model".

${ }^{27}$ Ver SCHOLL etali (2010, pp. 39-50). Vide, no Direito Internacional, o Programa "Compras Públicas Sustentáveis" (SPP), ação ligada ao Programa-Quadro de 10 Anos para Consumo e Produção Sustentáveis (10YFP). Vide, a respeito, www.unep.org/10YFP.

${ }^{28}$ Ver, por exemplo, o Acórdão 1.752/2011, do Tribunal de Contas da União.

${ }^{29}$ Ver "Guia prático de licitações sustentáveis da Consultoria Jurídica da União no Estado de São Paulo". São Paulo: AGU, 2011.

${ }^{30}$ Ver o "Guia de inclusão de critérios de sustentabilidade nas contratações da Justiça do Trabalho". Brasília: CSJT, 2012.
}

Revista do Direitoda UNISC, Santa Cruz do Sul, v.1, n. 45, p. 89-103, jan. - abri. 2015. 
No grupo das regras expressas, figura, com primazia cronológica, a Lei de Mudanças Climáticas. ${ }^{31}$ Esse diploma estipulou, com ousadia até, a cogência das escolhas que estimulem, de modo célere e indelével, ${ }^{32}$ o incremento de processos e tecnologias sustentáveis, destinados a contribuir para uma "economia circular", com o estabelecimento de preferência para propostas que propiciem maior economia de energia, água e outros recursos naturais. Note-se que tais critérios de preferência têm de ser aplicados até para a autorização administrativa e, "a fortiori", na celebração de contratos administrativos que pressupõem alta previsibilidade.

Outra disposição textual digna de nota restou inserida no corpo da Lei de Licitações, ${ }^{33}$ ao estatuir que o certame, além da isonomia, destina-se a garantir "a seleção da proposta mais vantajosa para a Administração e a promoção do desenvolvimento nacional sustentável." Como se observa, isonomia e sustentabilidade são princípios de aplicação consorciada obrigatória.

Por sua vez, a Lei do Regime Diferenciado de Contratações, ${ }^{34}$ teve o cuidado de sublinhar que os procedimentos licitatórios precisam guardar conformidade com o princípio do desenvolvimento sustentável e observar a diretriz da "maior vantagem para a Administração Pública, considerando custos e benefícios, diretos e indiretos, de natureza econômica, social ou ambiental, inclusive os relativos à manutenção, ao desfazimento de bens e resíduos, ao índice de depreciação econômica e a outros fatores de igual relevância." E não só: o diploma admite, na contratação de obras e serviços, a remuneração variável vinculada ao desempenho da contratada, com base em metas de sustentabilidade.

Já entre os objetivos da Política Nacional de Resíduos Sólidos, ${ }^{35}$ consta a prioridade mandatória, nas contratações públicas, para produtos reciclados e recicláveis, ${ }^{36}$ assim como bens, serviços e obras que

\footnotetext{
${ }^{31}$ Vide Lei $12.187 / 2009$.

${ }^{32}$ Ver, a propósito, as recomendações do Tribunal de Contas da União, em auditoria operacional sobre políticas públicas e mudanças climáticas, in TC 026.061/2008-6, Acórdão 2.462/2009.

${ }_{33}$ Vide Lei 12.349, de 2010, que alterou o art. 3o, da Lei de Licitações.

${ }^{34}$ Vide Lei 12.462, de 2011, arts. 3ํ, 4으, 10 e 19.

${ }^{35}$ Vide Lei 12.305 , de 2010, art. $7^{\circ}$, XI.

${ }^{36} \mathrm{~A}$ regulação estatal, por certo, é decisivo fator para a promoção da denominada economia circular. Com isso em mente, a Comissão Europeia formulou, recentemente, propostas ambiciosas de reciclagem, até 2030 .
}

Revista do Direitoda UNISC, Santa Cruz do Sul, v.1, n. 45, p. 89-103, jan. - abri. 2015. 
considerem critérios compatíveis com os padrões de consumo social e ambientalmente sustentáveis. Para esse diploma, sempre que viável optar entre um ou outro bem, a escolha tem que recair sobre aquele que estiver em sintonia com as exigências globais da sustentabilidade, sobremodo perante alternativas com preços razoáveis. O que se intenta, em outras palavras, é acelerar a transição para o mundo dos negócios "verdes," à base da constatação de que os métodos usuais ("business as usual") simplesmente tendem a tornar a vida humana seriamente deficitária. (NUSSBAUM; SEN, 1993, pp. 1-9)

O segundo grupo é o das regras administrativas expressas, as quais, no âmbito do poder regulamentar, visam a concretizar o princípio da sustentabilidade. Aqui, merece referência, a título ilustrativo, o Decreto 7.746, de 2012, ${ }^{37}$ que regulamenta 0 art. $3^{\circ}$, da Lei de Licitações, precisamente ao estabelecer os critérios explícitos de sustentabilidade nas contratações públicas. São listadas, entre outras diretrizes, a maior vida útil e o menor custo de manutenção, além da origem ambientalmente regular dos recursos utilizados nos bens, serviços e obras.

Diante do exposto, lícito asseverar que regras ${ }^{38}$ se encontram disponíveis, no sistema brasileiro, para exigir procedimentos sustentáveis. No entanto, caso perdure, aqui e ali, eventual lacuna, resta o caminho plausível de construir o intérprete, ${ }^{39}$ por interpretação sistemática, regras integrativas do terceiro grupo, isto é, aquelas formuladas pelo aplicador (fiel aos compromissos derivados do contrato social intergeracional), ${ }^{40}$ que não se subtrai do compromisso de contribuir à eficácia do citado princípio. A não ser assim, a suposta ausência de regras seria utilizada como arma contra a força vinculante do sistema, arma que nenhum agente idôneo tem o porte para carregar.

Em síntese, existem regras (dos três grupos) mais do que suficientes para se considerar imediatamente eficaz o princípio do desenvolvimento sustentável, no campo dos procedimentos públicos. Nada justifica que tais procedimentos permaneçam presos a metodologias míopes de julgamento e

\footnotetext{
${ }^{37}$ Vide a Instrução Normativa 10, de 2012.

${ }^{38} \mathrm{O}$ art. $3^{\circ}$, da Lei de Licitações, ao consagrar o princípio do desenvolvimento sustentável, veicula norma geral aplicável a todas as esferas federativas.

${ }^{39}$ Ver, nessa linha, FREITAS(2010, pp. 228- 271).

${ }^{40}$ Ver, sobre o tema, HABERLE(2009, pp. 17-37).
}

Revista do Direitoda UNISC, Santa Cruz do Sul, v.1, n. 45, p. 89-103, jan. - abri. 2015. 
controle, como se pudessem desprezar impunemente os direitos fundamentais de gerações presentes e futuras.

Portanto, os controles (externo, interno, social e jurisdicional) têm de assumir 0 protagonismo na redefinição da cultura publicista (administrativa, ${ }^{41}$ por exemplo) com determinações (não meras recomendações), voltadas ao balanceamento apropriado de custos e benefícios, em termos econômicos, sociais e ambientais. Consigne-se de forma cristalina: a sustentabilidade representa - à diferença do que imaginam os críticos superficiais - enorme ganho de eficiência, com redução mediata de custos (às vezes até no plano imediato). Bem assimilado, o princípio da sustentabilidade deixa de ser visto, pois, como marketing para ganho de reputação, e se converte numa fonte preciosa de agregação de valor.

Naturalmente, os critérios de sustentabilidade, incorporados ao processo de tomada da decisão pública, requerem impessoalidade, capacidade refinada de prospecção e abandono resoluto das concepções reducionistas (próprias da "patronagem" e do utilitarismo míope). Não é admissível manter os juízos adstritos ao curto prazo, típico comportamento daqueles que se alienam, por ação ou por omissão, a interesses subalternos ou autocentrados.

Nessa ótica, o gestor público e os controles devem vencer, em conjunto, qualquer traço de indolência acomodatícia, no encalço de estimular iniciativas aprováveis no teste de sustentabilidade. Logo, cresce de relevo examinar as políticas públicas mediante uma tríade de questões.

Uma primeira questão concerne aos antecedentes e à finalidade do procedimento público. Nessa fase interna, imprescindível responder às seguintes indagações, em resumo: É o procedimento público realmente necessário? Apresenta benefícios diretos e indiretos, intrínsecos e extrínsecos, que superam os custos diretos e indiretos? O agente público "lato sensu" considerou, com esmero de cálculo ${ }^{42}$, a hipótese de resolver a demanda, com medidas de racionalização ou o emprego daquilo que está disponível e ocioso? A decisão pública favorece o desenvolvimento sistêmico ou contribui para o desperdício e para a formação de gargalos que dificultam a vida de todos? 0

\footnotetext{
${ }^{41}$ Ver, por exemplo, Resolução 976/2013 e Resolução 1009/2014, do Tribunal de Contas do Rio Grande do Sul.

${ }^{42}$ Cálculo relativo à estima dos custos (diretos e indiretos) e benefícios ambientais, sociais e econômicos.
}

Revista do Direitoda UNISC, Santa Cruz do Sul, v.1, n. 45, p. 89-103, jan. - abri. 2015. 
dever de motivação, exercido nessa fase, tem de enfrentar, coerente e congruentemente, o mérito dessas questões em bloco, na certeza de que o procedimento supérfluo ou lesivo não pode ser aceito. Numa síntese: o que afeta o futuro, afeta direitos fundamentais, razão pela qual tem de estar satisfatoriamente ponderado e justificado.

Prosseguindo no teste de sustentabilidade: a segunda bateria de questões envolve a fase de implementação do procedimento público. Aqui, superada a etapa decisória inicial, é chegado o momento de definir os requisitos de ordem ambiental, econômica e social. Requisitos que, na etapa do julgamento, ultrapassam - sem excluir - o exame de legalidade e formas.

Por derradeiro, a terceira questão é aquela relativa à avaliação dos resultados. Nesse ponto, conferir-se-á se os resultados foram positivos, conforme aspectos comensuráveis e incomensuráveis, checando-se, assim, o cumprimento exato de condicionantes.

Os momentos, que compõem o teste de sustentabilidade dos procedimentos públicos, apresentam-se encadeados. Uma vez resolvidas essas questões reciprocamente implicadas, os critérios de sustentabilidade reorientam, por assim dizer, a governança pública, já pelo redesenho do bloco de sindicabilidade de seus objetivos concretos, já pela ressignificação dos elementos vinculados do julgamento em abstrato, já enfim pelo escrutínio da operacionalização. $^{43}$

Nesses moldes, a sustentabilidade proíbe a ineficiência e a ineficácia dos procedimentos públicos (finalidade inibitória), hierarquiza prioridades para a tutela de direitos fundamentais de gerações presentes e futuras (finalidade conformadora e hirarquizadora), ${ }^{44}$ obriga a prevenção e a antecipação, com antevisão de resultados (finalidade antecipatória e prospectiva), estimula e induz comportamentos intertemporalmente responsáveis (finalidade indutora e preventiva).(MISCHEL et ali 2010, pp. 1-5) Vale dizer, o procedimento público, aprovado no teste da sustentabilidade (com observância das regras correspondentes), é aquele concretizador de políticas constitucionais

\footnotetext{
${ }^{43}$ Nessa linha, ver, por exemplo, SILVA e BARKI (2012).

${ }^{44} \mathrm{Em}$ razão disso, novos métodos menos onerosos serão sempre preferíveis. Exemplo: o processo eletrônico será preferível, "prima facie", na comparação com os processos de consumo de papel, ainda que as licitações de informática tenham de considerar, adequadamente, a destinação de equipamentos digitais, como determina a Lei de Resíduos Sólidos.
}

Revista do Direitoda UNISC, Santa Cruz do Sul, v.1, n. 45, p. 89-103, jan. - abri. 2015. 
vinculantes (nos termos definidos antes). Pode parecer tarefa simples, mas não é. O maior inimigo reside nos desvios cognitivos que turbam a correção das decisões. ${ }^{45}$ Entretanto, nada autoriza o escapismo paralisante. Quando manejados sabiamente, os novos critérios operam como sofisticados padrões de juridicidade. Nessa medida, o exame de sustentabilidade dos custos e benefícios (diretos e indiretos) representa um verdadeiro alento para o Direito Público, um dos pontos mais promissores e ricos de inflexão dos estudos e das práticas publicistas.

\section{CONCLUSÕES}

Tudo considerado, a tomada da decisão pública (não apenas administrativa) terá de incorporar a análise de custos e benefícios diretos e indiretos (sociais, ambientais e econômicos), consoanteparâmetros do teste da sustentabilidade, ou seja, com aprovação no referido teste. Não se pretende a obediência exclusiva ao longo prazo (pois não se pode descurar do presente). Trata-se tão-só de reconhecer a relevância estratégica do Estado intergeracional, no intuito de reordenar o comportamento social - da base à cúpula - mediante políticas realmente norteadas pelo desenvolvimento sustentável.

Sublinhe-se: o princípio da sustentabilidade incide em todas as províncias do sistema jurídico, o que torna inadiável a sua exteriorização nas relações publicistas. Determina o emprego eficaz e decrescente de recursos naturais e a consecução de políticas capazes de alcançar uma resposta satisfatória aos desafios do desenvolvimento inclusivo e duradouro. Precisamente por isso, impõe-se erguersistema de avaliação das políticas públicas, que migre para o escrutínio de custos diretos e indiretos, sociais, ambientais e econômicos, de modo a viabilizar o Estado intertemporalmente responsável.

Em última análise, o princípio constitucional da sustentabilidade é uma diretriz que tem o condão de mudar, por inteiro, o edifício do Direito como sistema, não apenas pensado em moldes coercitivos, mas como poderoso

\footnotetext{
${ }^{45}$ Ver, sobre vieses, KAHNEMANet ali. (1982).
}

Revista do Direitoda UNISC, Santa Cruz do Sul, v.1, n. 45, p. 89-103, jan. - abri. 2015. 
indutor. Assim, o Direito Público cumprirá o papel indeclinável de incentivar a cooperação, a empatia e a preservação da biodiversidade. Passará a suscitar inovação, com fomento de modos de produção e consumo, compatíveis com o equilíbrio ecológico. Em suma, pode-se afirmar que o Direito precisa ser reconcebido, no Século XXI, sob o signo das energias limpas em sentido amplo.

\section{REFERÊNCIAS}

BAUMAN, Zygmunt. A Sociedade Individualizada. Rio de Janeiro: Zahar, 2008.

FERNÁNDEZ, Maria Jesús García-Torres. Análises de laProtección

Tributaria delMedio Ambiente. Cizur: Aranzadi-Thompson Reuters, 2011.

FREITAS, Juarez. Sustentabilidade: Direito ao Futuro. $2^{\mathrm{a}}$ ed. Belo Horizonte: Fórum, 2012.

2010.

A Interpretação Sistemática do Direito. $5^{\mathrm{a}}$ ed. São Paulo: Malheiros,

.Direito Fundamental à Boa Administração Pública. $3^{a}$ ed. São Paulo: Malheiros, 2014.

GIAMBIAGI, Fábio e BARROS, Octavio de (orgs.). Brasil Pós-Crise. Rio de Janeiro: Campus, 2009.

HÄBERLE, Peter. UnDerecho Constitucional para las Futuras Generaciones. La outra forma del contrato social: El Contrato Geracional. Lecciones y

Ensayos, n. 87, 2009, p. 17-37.

JEVONS, William Stanley. The Coal Question.Londres: MacMillan, 1866.

KAHNEMAN, Daniel; SLOVIC, Paul; TVERSKY, Amos (eds.). Judgment under Uncertainty: Heuristic and Biases. New York: Cambridge University Press, 1982.

MISCHEL,Walter; AYDUK,Ozlem; BERMAN, Marc; GOTLIB, Ian H.; JONIDES, John; KROSS, Ethan; TESLOVICH, Theresa; WILSON, Nicole L.; ZAYAS, Vivian; SHODA, Yuichi. Willpower over the life span: decomposing selfregulation," Social Cognitive and Affective Neuroscience Advance Access, Vol. 6, n. 4, 2010, pp. 354-359.

NUSSBAUM, Martha; SEN, Amartya (eds.). The Quality of Life. New York: Oxford University Press, 1993.

Revista do Direitoda UNISC, Santa Cruz do Sul, v.1, n. 45, p. 89-103, jan. - abri. 2015. 
SALZMAN, James; THOMPSON JR., Barton.Environmental Law and Policy. 3a ed. New York: Foundation Press, 2010.

SAMUELSON, William; ZECKHAUSER, Richard.Status Quo Bias in Decision Making. Journal of Risk and Uncertainty, Vol. 1, 1988, p. 7-59.

SCHOLL, Gerd; RUBIK, Frieder; KALIMO, Harri; BIEDENKOP, Katja; SILVA, Renato Cader da; BARKI, Teresa Villac Pinheiro. Compras públicas compartilhadas: a prática das licitações sustentáveis. Revista do Serviço Público, Vol. 63, n. 2, 2012, pp. 157-175.

SÖEBECH, Ólöf. Policies to promote sustainable consumption: innovative approaches in Europe. Natural ResourcesForum, Vol. 34, 2010, pp. 39-50. 